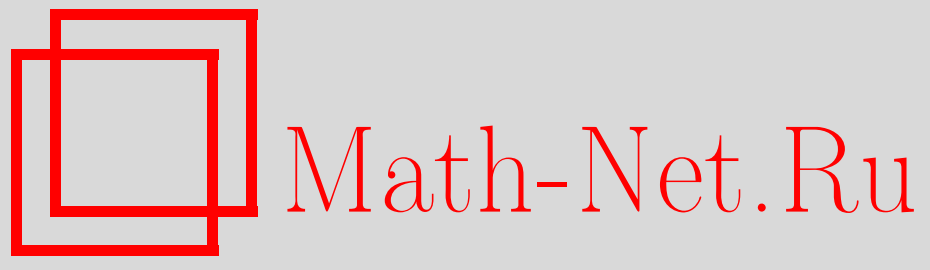

В. Клепцын, Добрыня и куча камней, Квант, 2019, номер 1, 35-38 DOI: https://doi.org/10.4213/kvant20190104

Использование Общероссийского математического портала Math-Net.Ru подразумевает, что вы прочитали и согласны с пользовательским соглашением http://www . mathnet.ru/rus/agreement

Параметры загрузки:

IP: 54.197 .217 .227

26 апреля 2023 г., 12:40:43

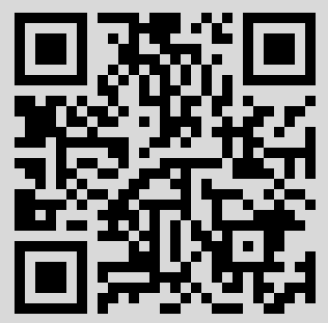




\section{Добрыня и куча камней}

\section{В.КЛЕПЦЫН}

Hisen А МАТЕМАТИЧЕСКОМ КРУЖКЕ УЧИтель только что закончил записывать условие задачи:

Есть куча из 1001 камня. Каждьй раз, когда богатырь Добрыня делит кучу камней на две, царь платит ему столько монет, каково произведение количеств камней в двух получившихся кучах. Как должен действовать Добрыня, чтобы получить как можно больше?

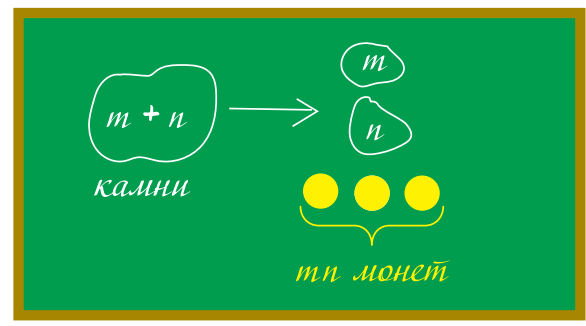

И сразу ученики заспорили.

- Ясно, что первым делом нужно поделить кучу почти пополам: тогда Добрыня сразу получит аж 500·501 монет. Потом меньшие кучи поделим еще пополам и т.д. А нам нужно будет весь этот заработок сложить. Только вот как? - сказала Женя.

- А кто тебе сказал, что этот путь самый выгодный? Пару раз сорвет куш, а потом будет он у тебя, скажем, десятимонетные кучки пополам делить, по 25 монет за раз получая. А у меня Добрыня по одному камню брать будет. Тысяча монет на первом ходу, 999 на втором, 998 на третьем... Тише едешь - дальше будешь! - ответил ей основательный Мика.

- Это что же, нам сейчас нужно будет все это складывать, чтобы сравнить? - Перспектива вычислять сумму тысячи слагаемых Женю явно не обрадовала.

- Не торопитесь, - вмешался учитель. Вы еще не «вжились» в задачу. Не спеши-

DOI: https://doi.org/10.4213/kvant20190104 те отвечать именно на заданный вопрос, попробуйте ее «покрутить» и поэкспериментировать, поймите, что происходит.

- Поэкспериментируешь тут, когда каждый раз тысячу чисел складывать надо, не согласилась Женя.

- Правильно. Поэтому для начала измените задачу. Число 1001 слишком большое, возьмите число поменьше и разберитесь с ним. А там, глядишь, и на исходный вопрос ответите.

- Один - замечательное число! Один камень в куче, делать ничего не надо, красота! Правда, и заработать у Добрыни не выйдет, - откликнулся на это предложение Мика.

- Два камня принесут Добрыне одну монету, тут без вариантов. А если их три, то $2+1=3$ монеты, - подхватила эстафету обрадовавшаяся Женя.

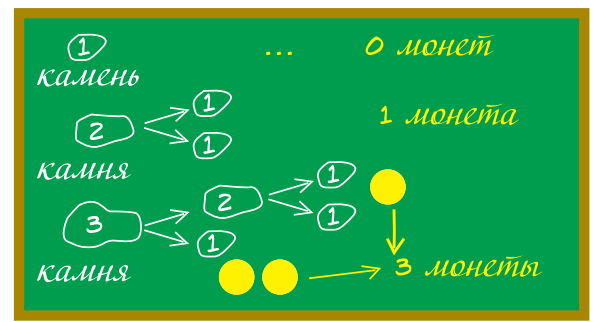

- Пусть теперь камней четыре. Если Добрыня поделит их пополам, а потом кучки опять пополам, как ты предлагаешь, то заработает $2 \cdot 2+1 \cdot 1+1 \cdot 1=4+1+1=6$ монет, - продолжил Мика.

- А если будет оттаскивать по одному камню, как предлагаешь ты, то $3+2+1=$ =6. Опять 6 монет! - удивилась Женя.

- А других вариантов нет. Смотрим на 5 камней?

- Смотрим! Если их поделить как $5=$ $=2+3$, то Добрыня заработает $2 \cdot 3=6$ монет первым ходом, а потом одну монету за кучку из 2 камней и три монеты за кучку 
из трех. Итого $6+3+1=10$ монет. А у тебя?

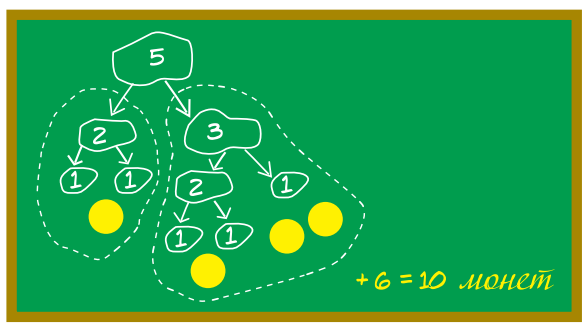

- Берем один камень и сводим задачу к предыдущей. Получается 4 монеты сразу и 6 потом. Итого $4+6=10$. Опять 10 ! Настал черед и Мики удивиться.

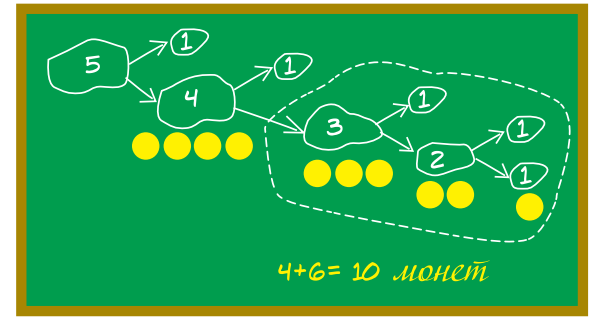

- Опять совпадение... А любое совпадение подозрительно. И должно быть исследовано! - подхватила Женя. - А не может ли так статься, что итоговый результат вообще не зависит от действий Добрыни? Ну, если только он не поленится и разберет все до конца?

- Проверим для 6 камней! - поддержал Мика. - Первым ходом Добрыня может поделить их как $1+5,2+4$ или $3+3$. Кучка из 2 камней приносит ему 1 монету, из 3 - три, из 4 - шесть, а из 5 - десять. Посмотрим-посмотрим:

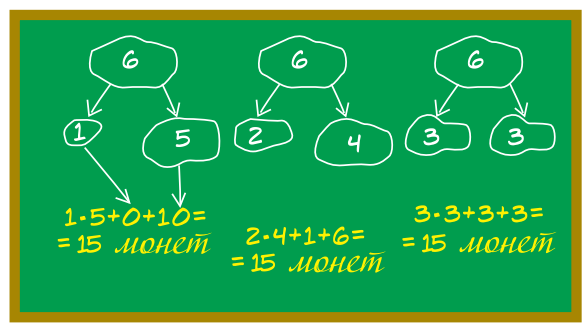

- Таких совпадений не бывает, мы были правы! - обрадовалась Женя. - Осталось это доказать. Где-то я эти числа видела: 1 монета, 3, 6, 10, 15...

- Да это же треугольные числа: ведь если Добрыня будет работать так, как я сказал, начав с кучки из $n$ камней, он заработает сумму последовательных чисел $(n-1)+(n-2)+\ldots+2+1$.

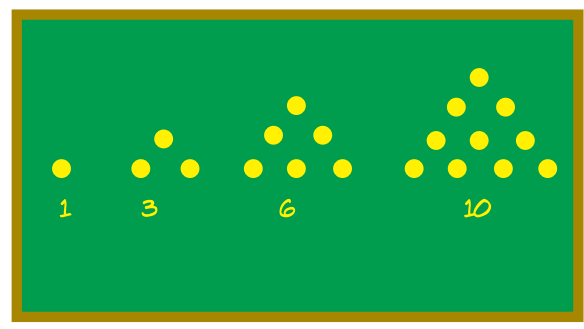

- Мы готовы сформулировать гипотезу, - обращаясь к учителю, Женя взяла на себя роль капитана. - Итоговый результат не зависит от действий Добрыни: когда куча из $n$ камней будет полностью разобрана, он получит $1+2+\ldots+(n-1)$ монет.

- Отлично! - обрадовался учитель. Вот вы и разобрались с тем, что в задаче происходит. Остается доказать. Сможете?

- Ну, это уже несложно, - подхватил Мика. - Сначала соберем треугольное число в более аккуратный вид: эта сумма равна $\frac{n(n-1)}{2}$. Потому что если ее удвоить, то монеты можно выложить в прямоугольник $n(n-1)$ :

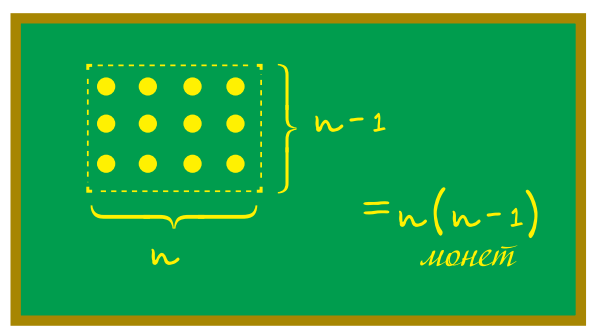

- А теперь посмотрим, - продолжил он. - Если сначала монет $n=a+b$ и Добрыня делит их на кучки из $a$ и $b$ монет, то первым ходом он заработает $a b$ монет, а потом еще $\frac{a(a-1)}{2}$ из первой и $\frac{b(b-1)}{2}$ из второй 
кучек. Всего

$$
\begin{gathered}
a b+\frac{a(a-1)}{2}+\frac{b(b-1)}{2}= \\
=\frac{2 a b+a^{2}+b^{2}-a-b}{2}= \\
=\frac{(a+b)^{2}-(a+b)}{2}=\frac{n^{2}-n}{2}=\frac{n(n-1)}{2} .
\end{gathered}
$$

- Ура! - обрадовался Мика.

- Формулы, формулы... А почему все же так хорошо совпало, что от действий Добрыни ничего не зависит? Нет ли этому какого-то хорошего объяснения? - задумалась Женя. - Ведь...

- Совпадения подозрительны! - подхватил Мика. - Может, получится это объяснить как-то геометрически? Ведь треугольное число - это когда складывают монеты треугольником; мы уже их так складывали, вычисляя, чему треугольное число равно.

- Но в таком треугольнике можно найти два меньших, соответствующих двум получающимся кучам из $a$ и $b$ монет! А останется как раз прямоугольник, и будет там как раз $a b$ монет! - обрадовалась Женя.

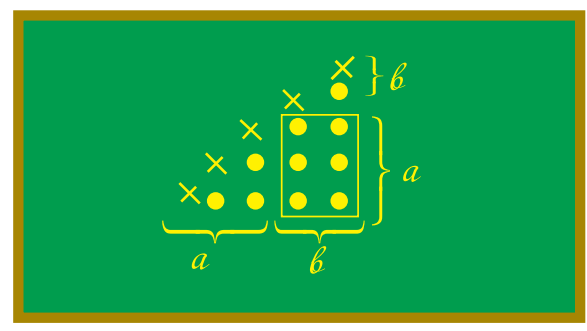

- Хорошо, это мы упростили рассуждение, обойдясь без формул. И получили красивое доказательство, почему формула работает; но хотели-то мы объяснения, почему результат от действий Добрыни оказался не зависящим, - не спешил радоваться Мика.

- Ты прав. Давай еще подумаем - что мы вообще о треугольных числах знаем? - не теряла энтузиазма Женя.

- Это еще количество пар. В смысле, сколькими способами можно выбрать два из $n$ камней, - ответил Мика.
- Количество пар... Ну конечно! Смотри, количество пар из $a+b$ камней - это количество пар из $a$ камней плюс количество пар из $b$ камней плюс количество пар, в которых один камень из первой кучи, второй из второй. Это тождество мы и написали, - азартно заговорила Женя. Вот тебе и объяснение! Давай свяжем веревочкой каждую пару камней в исходной куче. И пусть веревочки рвутся, когда камни оказываются в разных кучах. Тогда Добрыня, деля кучу на две, зарабатывает как раз столько монет, сколько веревочек он разорвал. Но в конце, когда у нас $n$ куч по одному камню, все веревочки будут разорваны. Значит, он заработал столько монет, сколько исходно было веревочек. Как бы он ни действовал!

- Молодцы! - подытожил учитель. Только не забудьте вернуться к исходной задаче и дать на нее ответ.

- Легко! - подхватил Мика. - Заработает Добрыня 500 ·1001 = 500500 монет, как бы он ни действовал, лишь бы не останавливался, пока все кучки не станут по одному камню.

- И еще раз - молодцы! А теперь к следующей задаче...

\section{Послесловие}

Автор исходной задачи - А.С.Меркурьев. Она была предложена в 1986 году на Ленинградской математической олимпиаде, а также вошла в «Задачник «Кванта» (М1001). Предлагаем для самостоятельного решения близкие к ней задачи.

1 (И.Изместьев). Имеется три кучи камней. Сизиф таскает по одному камню из кучи в кучу. За каждое перетаскивание он получает от Зевса количество монет, равное разности числа камней в куче, в которую он кладет камень, и числа камней в куче, из которой он берет камень (сам перетаскиваемый камень при этом не учитывается). Если указанная разность отрицательна, то Сизиф возвращает Зевсу соответствующую сумму. (Если Сизиф не может расплатиться, то великодушный Зевс позволяет ему совершать перетаскивание в долг.) В некоторый момент оказалось, что все камни лежат в тех же кучах, в которых лежали первоначально. Каков наибольший суммарный заработок Сизифа на этот момент? 
2 (Е.Горский). На доске написаны по возрастанию два натуральных числа $x$ и $y(x \leq y)$. Петя записывает на бумажке $x^{2}$, а затем заменяет числа на доске числами $x$ и $y-x$, записывая их по возрастанию. С новыми числами на доске он проделывает ту же операцию и т.д., пока одно из чисел на доске не станет нулем. Чему будет в этот момент равна сумма чисел на бумажке?

3 (Е.Горский, С.Дориченко). На доске написаны натуральные числа $x, y$ и $z$. Петя пишет на бумажку произведение двух из них, а на доске уменьшает третье число на 1. С новыми тремя числами на доске он делает ту же операцию и т.д., пока одно из чисел на доске не станет нулем. Чему в этот момент равна сумма чисел на бумажке?

Подсказка к задачам 2 и 3: придумайте геометрическую интерпретацию подсчета.

Рекомендуем для дальнейшего изучения статью Е.Бакаева «Мальчики, девочки, таблицы, графы...» («Квант» №3 за 2015 г.), в которой также обсуждается геометрический подход к подобным комбинаторным задачам. (Прим. ред.)

\section{КОНКУРС ИМЕНИ А.П.САВИНА}

Мы продолжаем очередной конкурс по решению математических задач. Они рассчитаны в первую очередь на учащихся 7-9 классов, но мы будем рады участию школьников всех возрастов. Конкурс проводится совместно с журналом "Квантик».

Высылайте решения задач, с которыми справитесь, электронной почтой по адресу: savin.contest@gmail.com или обычной почтой по адресу: 119296 Москва, Ленинский проспект, 64-A, “Квант" (с пометкой «Конкурс имени А.П.Савина"). Кроме имени и фамилии укажите город, школу и класс, в котором вы учитесь, а также обратный почтовый адрес.

Мы приветствуем участие в конкурсе не только отдельных школьников, но и команд (в таком случае присылается одна работа со списком участников). Участвовать можно, начиная с любого тура. Победителей ждут дипломы журнала “Квант" и призы. Задания, решения и результаты публикуются на сайте sites.google.com/view/savin-contest

Желаем успеха!

17. Есть 5 карточек с числами 3, 4, 5, 6, 7. Сколько из них можно сложить пятизначных чисел, делящихся на 55? (Карточку «6» нельзя переворачивать и использовать как «9».)

\section{П.Кожевников}

18. Петя и Вася купили по конструктору «Собери тетраэдр». В конструкторе 4 треугольника - будущие грани тетраэдра. По дороге Петя потерял один треугольник. Заметив это дома, он побежал с остатками своего конструктора к Васе. Сравнивая детали, они обнаружили, что среди четырех Васиных треугольников есть три таких же, как у Пети. «Отлично, теперь я знаю, какой треугольник я потерял!» воскликнул Петя. «Вот только почему цены конструкторов отличаются?» - задумался он. А могло ли быть так, что у ребят конструкторы отличались одним треугольником, но из каждого конструктора можно было собрать свой тетраэдр?
19. а) Найдутся ли 100 различных натуральных чисел, среднее арифметическое любых нескольких из которых - натуральное? б) А если добавить условие, что любые два числа из этих ста должны быть взаимно просты?

П.Кожевников

20. Дан клетчатый квадрат $100 \times 100$. Некоторые его клетки можно закрыть. Будем говорить, что доминошки $1 \times 2$ расположены в нем разрешенным образом, если каждая занимает ровно две незакрытые клетки и никакие две доминошки не имеют общего отрезка границы (но у доминошек могут быть общие вершины). Какое наименьшее количество клеток можно закрыть, чтобы: а) 2; б) 100 доминошек нельзя было расположить разрешенным образом?

Е.Бакаев 